\title{
Determinants of Living Arrangements among the Chinese Elderly: New Evidence from the CLHLS 2011 Wave
}

\author{
Zhang Li \\ China University of Political Science and Law, Beijing, China \\ Email: Izhang@cupl.edu.cn
}

Received 25 December 2014; accepted 13 January 2015; published 12 February 2015

Copyright (C) 2015 by author and Scientific Research Publishing Inc.

This work is licensed under the Creative Commons Attribution International License (CC BY). http://creativecommons.org/licenses/by/4.0/

(C) (i) Open Access

\begin{abstract}
This research examines the determinants of living arrangements among the Chinese elderly by distinguishing the seniors by sex, residence and age. Through analyzing data from the 2011 wave of Chinese Longitudinal Healthy Longevity Survey (CLHLS), the results show that about $80 \%$ of the elderly still chose to co-reside with other family members and only $2 \%$ of them lived in institutions. Having children nearby who visited frequently, high education, pension coverage and social integration generally decrease the odds of co-residing. Having activity of daily living (ADL) disabilities, higher household income, homeownership and preferring living with others increase the likelihood of co-residing. Currently married individuals, females and minorities are more likely to live with others. Co-residing also increases with age. However, the effects of the above factors on the subgroups' living arrangements differ substantially. Male and urban residents' living arrangement determinants are more similar, whereas female and rural residents' co-residing determinants are more comparable. Age of 75 is found to be a bench mark differentiating living arrangement patterns and determinants for seniors. The study draws future research attention to developing separate models understanding the elderly subgroups' living arrangements.
\end{abstract}

\section{Keywords}

The Elderly, Living Arrangements, Chinese Longitudinal Healthy Longevity Survey (CLHLS)

\section{Introduction}

As populations continue to age, research on determinants of the elderly's living arrangements has been expanding. Prior research based on analyzing the elderly in more developed countries has documented that the impor- 
tant factors conditioning the living arrangement decision of the elderly include availability of kin, economic resources, and health status (Wolf, 1984; Worobey \& Angel, 1990). As people age, the seniors' lives may be altered by the loss of spouse or the nest-leaving behavior of children. The elderly may also face new constraints in health or economic resources that make certain living arrangements possible or unaffordable. These changes and resources combined shape the elderly individual's capacity to act on the preference for whether living independently. Indeed, choosing where and with whom to live is a complicated decision for the elderly. Besides the well-documented determinants, there are a number of other factors that need to be considered, such as cultural preference, tradition, et al. Thus far, the generalizability of the findings based on analyzing seniors in western countries to the elderly in less developed countries, such as China, has not been established. Considering the unique social context of China which is experiencing a drastic social transformation and holds an Asian culture of filial piety towards the elderly, there is a reason to believe that the existing analysis of the elderly's living arrangements needs to be re-evaluated when applied to the Chinese society.

When studying living arrangements of the Chinese elderly, there is also a need to analyze rural and urban residents separately due to the large disparities in socioeconomic life existing between urban and rural parts of the country. Urban residents generally enjoy better social security benefits, medical care, and health services as compared to their rural counterparts, which may impact the rural and urban elderly's living arrangements. Meanwhile, modernization theories propose that urbanization and industrialization decrease intergenerational co-residence. Under this assumption, urban and rural residents may have different living arrangement patterns and determinants giving their different paces of urbanization.

Besides rural and urban differentiation, the elderly's living arrangements may also differ significantly by gender and age. The gender differences among the elderly have long been highlighted numerous times in the literature. For example, females enjoy a longer life expectancy but may have greater economic disadvantages in general as compared to males. Durkheim has suggested that the protective effect of marriage for men and women is not equal. "Women can suffer more from a marriage if it is unfavorable to her than she can benefit by it if it conforms to her interest. This is because she has less need of it (Durkheim, 1951: p. 275).” In addition to gender, age affects the elderly's living arrangements too. With people aging, various life events and family changes often occur, such as family structure change, losing their spouse, et al. Thus, it makes sense to speculate that the elderly's living arrangements and determinants may vary by age.

Thus far, few studies have showed the living arrangement patterns of the Chinese elderly, especially by residence, gender and age. Models have hardly been developed to explain the elderly's living arrangements of different subgroups. Using data from the Chinese Longitudinal Healthy Longevity Survey (CLHLS), the paper intends to fill the voids of the prior literature by demonstrating the living arrangement patterns by subgroup of the elderly and establishing separate models for these groups' living arrangements. Meaningful policy implications are expected to be drawn from the research to better deal with the living arrangement issues associated with rapidly growing aging population.

\section{Living Arrangements of the Chinese Elderly}

I first summarize the living arrangements of elderly by referring to Table 1 . The data show the variation of living arrangement patterns for elderly in China aged 65 and above. Three types of living arrangements are classified in this research, which include: 1) living alone, 2) living with others, and 3) institutionalization (mainly nursing homes). The elderly are analyzed by subgroups: rural vs. urban, male vs. female, and three age groups (65 to 74, 75 to 84, and 85 and over). The data are derived from the newly released CLHLS wave 2011-2012 dataset, which are described more fully in the section on data and methods.

As the table shows, for both male and female elderly individuals, living with other household members is the modal category (around $80 \%$ ) regardless of their residence (rural or urban), gender or age. Overall, only about $2 \%$ of the sampled elderly lived in institutions. The rest of the elderly chose to live alone. Diversity, however, exists with regard to living arrangements among the subgroups. Specifically, men are more likely to live with other household members as compared to women (83.3\% vs. $79.1 \%)$. This is perhaps due to a higher marriage rate of men than women since living with spouse is also included in the "living with other household members" category. Urban residents are more likely to live with other household members than their rural counterparts (82\% vs. $80 \%)$. Accordingly, there are a higher percentage of women who lived alone than men (18.6\% vs. $14.8 \%)$ and a higher percentage of rural residents than urban residents who lived alone. Meanwhile, the percentage of 
Table 1. Percentage distribution of living arrangements among elderly aged 65 and over: China, 2011.

\begin{tabular}{|c|c|c|c|c|c|c|c|}
\hline \multirow{2}{*}{ Living Arrangements } & \multicolumn{2}{|c|}{ Sex } & \multicolumn{2}{|c|}{ Residence } & \multicolumn{3}{|c|}{ Age Group } \\
\hline & Male & Female & Urban & Rural & $65-74$ & $75-84$ & $85+$ \\
\hline Living with household members & 83.3 & 79.1 & 82.0 & 80.0 & 85.8 & 78.1 & 80.3 \\
\hline Living alone & 14.8 & 18.6 & 14.9 & 18.7 & 13.5 & 20.5 & 16.6 \\
\hline Institution & 2.0 & 2.3 & 3.1 & 1.3 & 0.7 & 1.4 & 3.1 \\
\hline $\mathrm{N}$ & 4,349 & 5,288 & 4,571 & 5,066 & 1,911 & 2,526 & 5,115 \\
\hline
\end{tabular}

Source: CLHLS wave 2011.

urban residents who were institutionalized is also higher than that of their rural counter parts ( $3.1 \%$ versus $1.3 \%$ ).

When age is taken into consideration, it is shown that the percentage of individuals who were institutionalized increase with age. Elderly aged 65 to 74 are more likely to live with other household members as compared to the other two age groups. The elderly aged 75 to 84 reported the highest percentage of living alone (20.5\%). This age group is also least likely to live with others as compared to other two age groups.

In summary, although the majority of the elderly studied chose to live with other household members, living arrangement patterns vary by sex, age and residence. The variation may be the result of compound effects of various factors, including economic resources, availability of kin, cultural preference, health status and so on. The variation of living arrangements shown in Table 1 points to the necessity of testing models of living arrangements for different subgroups. Below I discuss the framework that I will use to conduct the current analyses of living arrangements among the Chinese elderly. The discussion also calls for research attention to subgroup variation when modeling elderly people’s living arrangements.

\section{Conceptual Framework}

\section{1) Available Kinship Network}

The first factor that impacts elderly living arrangements recognizes that the size and composition of one's kinship network is a major constraint on choice of living arrangements among the elderly. This is because the availability of kin helps an elderly person to delay or avoid formally entering long-term care institutions through receiving informal support or care given by the kinship network. Most people do not live alone or in an institution if they have other family members alive. The kinship network includes a variety of dimensions. Adult offspring are typically identified as the major component of the network because they provide care and assistance (financial or otherwise) when necessary. Researchers have found that characteristics of the kinship network, such as number of children and the demographic and socioeconomic profile of the children largely shape the availability of choices for living arrangements (Burr \& Mutchler, 1992; Wolf \& Soldo, 1988). Based on analyzing data from the CLHLS wave 1998, Guo Zhigang (2002) has shown that whether the elderly had surviving offspring is the key that determines if the elderly chose to live independently. Put differently, the availability of offspring decreases the likelihood of living alone or institutionalization. But other researchers argued that number of children may be less dominant when other characteristics, such as health, income, and demographic factors are controlled (Worobey \& Angel, 1990). The mixed results indicate that more research is necessary to evaluate the association between kin availability and elderly living arrangements.

Besides number of children, decisions to co-reside may be also influenced by the gender composition of adult children. In many Asian countries, it is usually preferable to co-reside with sons because of cultural norms. Thus, it is reasonable to expect that the Chinese elderly to be more likely to live with children if they have sons due to the cultural norms. Additionally, prior research showed that the distance from children and frequency children visit the elderly also determine the quality and frequency of caregiving (Li, Zhang, \& Liang, 2009). All these findings provide basic framework for this analysis.

In China and many other countries, rural residents experience higher fertility than their urban counterparts. The higher fertility may result a larger family size which may foster a greater likelihood of co-residence among rural residents. Meanwhile, the variation of kin availability for elderly living arrangements also exists among different gender and age groups. So far, how elderly's living arrangements are influenced by their kin networks 
among subgroups in China has not been fully addressed in the literature. This issue becomes one of the major concerns of this research and will be explored in the current study.

\section{2) Health Status}

In addition to available resources including informal support from family members and kinship network, health is an important factor the elderly people consider when making living arrangement decisions. Health status, particularly the level of functional ability, constrains the living arrangement choices. It shapes the amount of independence and level of autonomy that the elderly people can retain. The elderly with good health can make decision on their living arrangements with a modified set of constraints and opportunities because they require no physical assistance. People with an intermediate level of health are more likely to make living arrangement decisions by taking their needs for assistance into consideration. Individuals with poor health are more likely to be institutionalized and less likely to live alone than those with better health. Generally speaking, disability may lead to a higher likelihood of institutionalization (Worobey \& Angel, 1990). Institutionalization also frequently results from a need for intensive medical assistance because in-home care under these circumstances may be even more costly than institutional care (Soldo, 1980).

A previous study using CLHLS found that among the oldest-old, institutionalized persons are younger, male, urban, have less family-care resources and have worse health than those who lived in the community (Gu, Dupre, \& Liu, 2007). Another research indicated that many Chinese seniors in institutions did not have chronical health conditions but chose to live in old-age homes because they were lack of family and economic resources (Wu \& Caro, 2009). These findings based on the Chinese social context seem to be mixed. In this article, I intend to provide a clearer picture of the link between health characteristics and the living arrangements among the subgroups.

\section{3) Economic Resources}

The third factor concerns the socioeconomic resources that make living arrangement options feasible. Previous research has shown that there is a positive association between economic resources and living independently. The older adults who chose to live alone tend to have higher socioeconomic status and better material circumstances as compared to other older adults (Mutchler \& Burr, 1991). The elderly tends to maximize their independence if their economic status allows them to do so. This argument has been supported by research on the Chinese elderly. Zhang Zhen (2001) analyzed data from the 1998 CLHLS and found that the elderly who were economically doing well had more options in choosing their living arrangements and tended to live independently when other factors were controlled.

Besides income, education and occupation that are commonly used measures of one's socioeconomic status, other indicators of socioeconomic status have been utilized in the previous studies. Pension, for example, has been considered as an important economic source for some elderly. Based on analyzing 1900, 1910 and 1950 census data of the US, Costa $(1997,1999)$ has found that receiving pension increased the likelihood of elderly living independently. In a similar vein, Engelhardt and associates (2005) studied samples from 1980 to 1999 surveys of elderly and found similar results. Other research, however, showed that receiving pension had no significant impact on living arrangements of the elderly in less developed areas (Edmonds, Mammen, \& Miller, 2005). When it comes to the case of China, through analyzing the 2000, 2002 and 2005 CLHLS data, Shen Ke (2010) documented that in China, pension coverage indeed led to an increase of elderly living with other household members. This is because pension served as a form of wealth that attracts offspring to live with elderly and provide care.

In addition to pension, factors relate to housing is also an economic concern that determines living arrangements. When housing costs are high or increasing, parents and children live together can save money, which increases the likelihood of co-residing. Under such a circumstance, the elderly provides housing for children or it could be a push factor for the elderly to live independently. Previous research has documented a significant rural and urban difference that co-residence is more prevalent in urban than in rural areas in Asian countries due to the shortage of housing (Kim \& Choe, 1992). Elderly who could provide housing to the offspring attract them to live together. In rural areas, especially when children move out to cities to seek job opportunities, the likelihood of co-residence is lessened. These rural and urban differences again point out the necessity of differentiating rural and urban elderly subgroups when studying living arrangements. The main payers of monthly bills have also been used to indicate of the economic status of the elderly. This factor will be included in this analysis as well.

\section{4) Other Factors}

Beyond the factors discussed above, previous research has also emphasized that social integration or social 
participation influences the elderly's living arrangement decisions. For example, Chen Yen-Jong and Chen Ching-Yi (2012) found that social participation enhances social support for the elderly and thus lowers the likelihood of the elderly to reside with their children. Social participation or social integration includes two parts. One is informal networks, such as involvement with friends and relatives and the other one is formal engagement, such as participation in paid employment, clubs, and other organizations, caregiving, and church activities. The elderly engaging in various degrees of social interaction with others and the environment leads to different levels of emotional dependence and perceived social support, which may influence the elderly's living arrangement patterns.

Moreover, people's preference for independent living in old age has also been found to be an important factor affects living arrangement patterns (Li et al., 2009). This is partially related to cultural norms regarding family roles and filial responsibility. Eastern countries tend to highlight more of filial responsibility and therefore people are more likely to prefer co-reside than western countries.

Despite the extensive literature on elderly living arrangements and the determinants in both more developed and less developed countries, few studies have developed a relatively comprehensive model of living arrangement determinants for the Chinese elderly, especially for subgroups. This research refers to the basic framework provided by prior studies and takes the availability of kinship network, economic resources, health status and other factors into consideration to explore appropriate models explaining determinants of the subgroups' living arrangements. I now turn to the discussion of the data, variables and methods.

\section{Data and Measures}

\subsection{Data}

Data used for this analysis are from newly released wave of the Chinese Longitudinal Healthy Longevity Survey (CLHLS), "the first large surveys of the oldest old conducted in a developing country" (Zeng, Vaupel, Xiao, Zhang, \& Liu, 2002: p. 252). I analyzed newly released data collected in 2011 and 2012. The CLHLS data were collected by Peking University's Center for Healthy Aging and Family Studies and the China National Research Center on Aging, with support from the US National Institute on Aging.

The 2011-2012 CLHLS wave was undertaken in more than 800 randomly selected counties and cities of the 23 provinces in China (Liaoning, Jilin, Heilongjiang, Beijing, Tianjin, Shanxi, Shaanxi, Shanghai, Jiangsu, Zhejiang, Anhui, Fujian, Jiangxi, Shandong, Henan, Hubei, Hunan, Guangdong, Guangxi, Sichuan, Chongqing and Hainan). The survey covers roughly half the counties and cities of those provinces and the sample areas represent $85 \%$ of the total population of China. In the 2011-2012 survey, 3802 male elderly and 4603 female elderly (for a total of 8405) surveyed in 2008 were reinterviewed. And 801 males and 982 females (for a total of 1783) were newly added interviewees. Thus, in the 2011 wave, 4603 males and 5585 females were included in the survey. In my analysis, I excluded those under 65 years of age, which yields a total number of studied elderly as 9679 ranged from 65 to 114 years old.

\subsection{Measures}

\section{1) Measuring Living Arrangements}

Living arrangements in this study is measured by three sub-categories: 1) living with others, 2) living alone, and 3) living in institution. When I conducted regression analysis to study the determinants of living arrangements, I coded those living with other household members as " 1 " and "0" if otherwise because "living with others" represents the majority of the surveyed respondents.

\section{2) Measuring Kinship Network}

This set of covariates relates to the availability of children and the frequency children visited their parents. The measures include number of children ever born, number of sons and daughters alive at present, and whether the respondent had children lived nearby but not in co-residence frequently visited the respondent (yes $=1$, no $=$ 0 ). Nearby was defined as living in the same village, neighborhood, township, city or county of the respondent.

\section{3) Measuring Health Status}

The heath measures are self-rated health (SRH), ADL disability and chronic conditions. SRH is defined as one's assessment of his/her own health. The survey asked the respondent to rate his or her health on a 5-point scale ( $5=$ very good, $4=$ good, $3=$ so so, $2=$ poor and $1=$ very poor). ADL disability is defined as whether the 
respondent had limitations in activities of daily living (ADL) at the 2011 wave. ADL is measured by six items (bathing, dressing, using the toilet, indoor transferring, eating, and controlling bladder and bowel movement). Being incapable to perform any of the six activities independently is considered as having ADL. The ADL score can therefore range from 0 to 6 . I coded ADL into a categorical variable $(1=$ yes, $0=$ no). Regarding chronical illness, the survey asked the respondent to report the illnesses the person had on a list of illnesses (e.g., diabetes, heart disease, hypertension, stroke, cancer). I initially planned to use variable generated from this question to measure the chronic illness. Nevertheless, I found the number of cases for the variable was limited. Thus, I decided to use a different measure which asked the respondent number of times suffering from serious illness within the past two years. The chronic condition variable is coded as a dichotomous variable if the person suffered from chronical illnesses (yes $=1,0=$ no).

\section{4) Measuring Economic Condition}

Average household income prior to the survey year is the first measure used to measure the economic status of the elderly. Education captures a second broad dimension of socioeconomic status and is measured as the number of years of completed schooling reported by each individual. Occupation is also used as an indicator of economic status. Occupational status is measured as high (professional and technical personnel, administrative or managerial positions) versus low (all others, e.g., agricultural, industrial, service and fishery workers, military personnel) based on the respondent or his or her spouse's occupation before the age of 60 . In addition to these measures, I also considered pension and homeownership. Older people in urban areas are likely to receive retirement income than those in rural areas. It is coded as " 1 " if the elderly had pension coverage and " 0 " if otherwise. Similarly, if the respondent owned a residence then it is coded as " 1 " and " 0 " if otherwise. The primary source of daily expenses is the last measure of the elderly's socioeconomic resources. It is coded as " 1 " if the elderly paid the expenses by him or herself and "0" if otherwise.

\section{5) Measuring Other Factors}

In this analysis, I also include measures of social integration and living arrangement preferences. Social integration is measured by the question: "Do you take part in some social activities at present?" The options for the elderly to choose include: almost every day, once a week, once a month, sometimes and never. I coded participating in social activities as " 1 " and " 0 " if never doing so. In the CLHLS questionnaire, there is a question that asked the respondent what kind of living arrangements the elderly liked the most. The choices offered to the elderly are: living alone, living alone or with spouse only, co-residence with children and institution. Living arrangement preference variable is coded as a categorical variable in this analysis. Preferring to live with others is coded as " 1 " and " 0 " if otherwise.

In additional to the above measures, a number of variables are also controlled. These variables include the elderly's age which is measured in chronological years. Moreover, I also control the respondent's marital status (widowed, never married, divorced/separated), residence and ethnicity (Han vs. Non-Han) in separate models.

\subsection{Methods}

Since living with other family members represent the majority of the respondents and the dependent variable is coded as a dichotomous variable, I use logistic regression to conduct the analyses. I examine how the covariates listed above influence the living arrangements of different elderly subgroups, when the demographic and other factors are controlled. Models are run separately for each subgroup. I report regression coefficients here but tables with odds ratios and standard errors are available upon request.

\section{Results}

\subsection{Description of the Sample}

The descriptive results of the independent and control variables are shown in Table 2. I describe the characteristics of the sample based on the classification of the subgroups. In terms of kin availability, the respondents reported an average number of children ever born (CEB) as 4.3. Women reported a higher CEB than men, and the elderly aged 65 - 74 reported a lower CEB than the other two age groups. The average number of sons is greater than that of daughters (1.9 vs. 1.8). Close to $90 \%$ of the elderly claimed that they had children living nearby who visited them frequently. There do not seem to be significant differences across the subgroups among the kin availability variables. 
Table 2. Descriptive analysis of independent and control variables for elderly aged 65 and over: China, 2011.

\begin{tabular}{|c|c|c|c|c|c|c|c|c|}
\hline \multirow{2}{*}{ Variables } & \multirow[t]{2}{*}{ All } & \multicolumn{2}{|c|}{ Sex } & \multicolumn{2}{|c|}{ Residence } & \multicolumn{3}{|c|}{ Age Group } \\
\hline & & Male & Female & Urban & Rural & $65-74$ & $75-84$ & $85+$ \\
\hline \multicolumn{9}{|l|}{ Kinship network variables } \\
\hline 1) Number of children ever born & 4.3 & 4.1 & 4.5 & 4.3 & 4.4 & 3.6 & 4.5 & 4.5 \\
\hline \multicolumn{9}{|c|}{ 2) If children lived nearby frequently visited (\%) } \\
\hline $1=$ yes & 88.9 & 89.0 & 88.7 & 89.3 & 88.3 & 90.3 & 89.6 & 87.9 \\
\hline $0=$ no & 11.1 & 11.0 & 11.3 & 10.7 & 11.7 & 9.7 & 10.4 & 12.1 \\
\hline 3) \# of sons alive & 1.9 & 1.9 & 1.9 & 1.9 & 2.0 & 1.8 & 2.1 & 1.9 \\
\hline 4) \# of daughters alive & 1.8 & 1.8 & 1.8 & 1.7 & 1.8 & 1.6 & 2.0 & 1.7 \\
\hline \multicolumn{9}{|l|}{ Health status variables } \\
\hline 1) Self-rated health & 3.3 & 3.4 & 3.3 & 3.4 & 3.3 & 3.4 & 3.3 & 3.4 \\
\hline \multicolumn{9}{|l|}{ 2) ADL (\%) } \\
\hline $1=$ yes & 26.4 & 20.3 & 31.5 & 24.0 & 29.1 & 31.7 & 31.5 & 40.9 \\
\hline $0=$ no & 73.6 & 79.7 & 68.5 & 76.0 & 70.9 & 68.3 & 68.5 & 59.1 \\
\hline \multicolumn{9}{|l|}{ 3) Chronical illness (\%) } \\
\hline $1=$ yes & 22.2 & 23.4 & 21.3 & 26.3 & 18.5 & 20.6 & 25.9 & 21.1 \\
\hline $0=$ no & 77.8 & 76.6 & 78.7 & 73.7 & 81.5 & 79.4 & 74.1 & 78.9 \\
\hline \multicolumn{9}{|l|}{ Economic resources variables } \\
\hline 1) Household income of last year & 24,869 & 25,622 & 24,238 & 30,703 & 19,679 & 24,134 & 24,562 & 25,342 \\
\hline 2) Education & 2.3 & 3.9 & 1.0 & 2.9 & 1.8 & 4.2 & 2.5 & 1.4 \\
\hline \multicolumn{9}{|l|}{ 3) High occupational status (\%) } \\
\hline $1=$ yes & 7.5 & 13.0 & 3.0 & 11.9 & 3.1 & 10.5 & 9.5 & 5.5 \\
\hline $0=$ no & 92.5 & 87.0 & 97.0 & 89.1 & 96.9 & 89.5 & 90.5 & 94.5 \\
\hline \multicolumn{9}{|l|}{ 4) Had pension (\%) } \\
\hline $1=$ yes & 19.3 & 28.4 & 11.9 & 32.3 & 7.7 & 24.9 & 24.1 & 15.1 \\
\hline $0=$ no & 80.7 & 71.6 & 88.1 & 67.7 & 92.3 & 75.1 & 75.9 & 84.9 \\
\hline \multicolumn{9}{|l|}{ 5) Homeownership (\%) } \\
\hline $1=$ yes & 88.8 & 88.0 & 89.4 & 81.2 & 95.4 & 87.4 & 88.3 & 89.4 \\
\hline $0=$ no & 11.2 & 12.0 & 10.6 & 18.8 & 4.6 & 12.6 & 11.7 & 10.6 \\
\hline \multicolumn{9}{|c|}{ 6) If main financial cost is self-covered (\%) } \\
\hline $1=$ yes & 20.7 & 28.0 & 14.8 & 33.7 & 9.0 & 29.6 & 25.9 & 15.0 \\
\hline $0=$ no & 79.3 & 72 & 85.2 & 66.3 & 91.0 & 70.4 & 74.1 & 85.0 \\
\hline \multicolumn{9}{|l|}{ Other variables } \\
\hline \multicolumn{9}{|l|}{ 1) Social integration (\%) } \\
\hline $1=$ yes & 13.9 & 18.0 & 12.5 & 18.7 & 9.6 & 23.7 & 18.4 & 8.0 \\
\hline $0=$ no & 86.1 & 82.0 & 89.5 & 81.3 & 90.4 & 76.3 & 81.6 & 92.0 \\
\hline 2) Living arrangement preferences & & & & & & & & \\
\hline $1=$ alone & 13.6 & 16.5 & 11.1 & 15.4 & 11.9 & 22.3 & 17.2 & 8.0 \\
\hline 2 = with spouse & 29.9 & 35.3 & 25.3 & 21.4 & 30.4 & 40.2 & 35.8 & 22.3 \\
\hline 3 = with children & 54.2 & 45.6 & 61.6 & 52.3 & 56.0 & 36.1 & 44.8 & 67.0 \\
\hline $4=$ institution & 2.3 & 2.7 & 2.0 & 2.9 & 1.7 & 1.4 & 2.2 & 2.6 \\
\hline Control variables & & & & & & & & \\
\hline 1) Currently married (\%) & & & & & & & & \\
\hline $1=$ yes & 61.8 & 57.3 & 22.6 & 38.4 & 38.2 & 26.0 & 48.0 & 17.3 \\
\hline $0=$ no & 38.2 & 42.7 & 77.4 & 61.6 & 61.8 & 74.0 & 52.0 & 82.7 \\
\hline 2) Minority (\%) & & & & & & & & \\
\hline $1=$ yes & 5.9 & 5.4 & 6.3 & 4.8 & 6.9 & 5.8 & 5.7 & 6.0 \\
\hline $0=$ no & 94.1 & 94.6 & 93.7 & 95.2 & 93.1 & 94.2 & 94.3 & 94.0 \\
\hline 3) Sex (\%) & & & & & & & & \\
\hline 1 = Male & 45.0 & - & - & 45.9 & 44.3 & 55.3 & 51.3 & 37.6 \\
\hline $0=$ Female & 55.0 & - & - & 54.1 & 55.7 & 44.7 & 48.7 & 62.4 \\
\hline 4) Urban (\%) & & & & & & & & \\
\hline $1=$ yes & 47.3 & 48.2 & 46.6 & - & - & 46.7 & 49.4 & 47.1 \\
\hline $0=$ no & 52.7 & 51.2 & 53.4 & - & - & 53.3 & 50.6 & 52.9 \\
\hline Age & 86.0 & 83.3 & 88.1 & 85.8 & 86.2 & - & - & - \\
\hline
\end{tabular}

Source: CLHLS wave 2011. N = 9679. 
When it comes to the health status of the elderly, the average self-rated health (SRH) of the elderly is 3.3, meaning on average, the sampled Chinese elderly self-rated their health status as anywhere between "so-so" to "good". There is no significant variation among the subgroups on SRH. Comparison of the elderly's ADL disabilities and chronical illnesses variables, the results show visible differentiation among subgroups. For the whole sample, $26.4 \%$ of the elderly reported having ADL disabilities. When subgroups are considered, there are higher percentages of females (31.5\%) and rural residents (29.1\%) reported having ADL disabilities. The results show that ADL disabilities also vary by age. The oldest-old show the lowest percentage reporting ADL disabilities (10.2\%) as compared to other two age groups. As to chronical illnesses, around one-fifth of the elderly claimed that they had suffered from chronical illnesses prior to the survey year. Men, urban residents and the elderly aged 75 to 84 show higher percentages of suffering from chronical illnesses (23.4\%, $26.3 \%$ and $25.9 \%$, respectively).

As expected, the socioeconomic status of the subgroups differs considerably. To illustrate, the urban elderly reported an average household income prior to the survey year as 30,703 RMB, which is way above the average household income reported by the overall sample. In contrast, their rural counterparts only reported an average household income in the same year as 19,679 RMB. As to educational attainment, males, urban residents and younger elderly all claimed a greater number of years of schooling. Around $7.5 \%$ of the elderly reported high occupational status before retirement (professional and technical personnel, administrative or managerial positions). There are also substantially higher percentages of males and urban residents who had higher occupational status before retirement than their female and rural counterparts. Pension data show that overall only about $19.3 \%$ of the elderly received pension. Males, urban residents and the younger elderly again show advantages in the pension coverage, especially that the urban residents reported 32.3\% of pension coverage, which ranked the highest among the subgroups. The homeownership data reveal that about $88 \%$ of the respondents owned their homes. Rural residents show the highest percentage of homeownership among subgroups. When the main source of financial support is concerned, about $20.7 \%$ of the whole sample reported they and their spouses covered the main daily costs. Males and urban elderly again show higher percentages in terms of being financially independent. These data highlight remarkable socioeconomic differences among the Chinese elderly subgroups.

The level of social participation also shows variation among subgroups though the majority of the respondents (86.1\%) reported not taking part in social activities. In general, females and rural residents tended to participation in social activities less and the level of social participation decreases with age. When it comes to the living arrangement preference, overall, over half of the elderly preferred to live with children, followed by living with spouse. They preferred least to live in institutions. Gender differences are shown as a higher percentage of females than males preferred to live with children; higher percentages of males preferred to live alone, live with spouse or in institutions. Rural and urban differences are demonstrated as higher percentages of urban than rural elderly preferred to live in institutions or live alone. Rural elderly tended to prefer living with spouses or children. With age increasing, the percentages of elderly preferring to live alone or live with spouse decreases, but more of them preferred to live with children or in institutions. This is perhaps due to their needs of daily care from children or professionals.

As to the demographic controls, $61.8 \%$ of the respondents reported being married in the survey year. The rest of them were divorced, widowed, or never married. Apparently, males reported a much higher percentage of being married than females ( $57.3 \%$ vs. $22.6 \%$ ). There is no significant rural and urban difference in marital status. The distribution of Han majority and non-Han minorities are about equal among subgroups. Among the sampled elderly, there are a slightly higher percentage of them living in urban areas than rural areas (52.7\% vs. 47.3\%). The mean age of the sampled 9679 elderly is 85.9 and the respondents' ages range from 65 to 114 . There are also more females who were interviewed in the survey than males (55\% vs. $45 \%)$. After showing the differentiation among subgroups in various dimensions, I now turn to the regression analyses for subgroups.

\subsection{Regression Results}

Table 3 provides the logistic regression coefficients for separate models. The first model contains the results for all sampled elderly. In this analysis, I examine the relative odds of living with other household members as compared to the odds of not doing so. The analysis focuses on the effects of availability of kinship network, health status, economic resources and other related factors, controlling for demographic variables. The results show that after controlling for age, sex, marital status, ethnicity and urban residence, the children ever born 
Table 3. Logistic regression of the Chinese elderly's living arrangements on selected factors: Chinese aged 65 and over, 2011.

\begin{tabular}{|c|c|c|c|c|c|c|c|c|}
\hline \multirow[b]{2}{*}{ Variables } & \multirow{2}{*}{$\begin{array}{c}\text { All } \\
\text { Model } 1\end{array}$} & \multicolumn{2}{|c|}{ Sex } & \multicolumn{2}{|c|}{ Residence } & \multicolumn{3}{|c|}{ Age Group } \\
\hline & & $\begin{array}{c}\text { Male } \\
\text { Model } 2\end{array}$ & $\begin{array}{c}\text { Female } \\
\text { Model } 3\end{array}$ & $\begin{array}{c}\text { Urban } \\
\text { Model } 4\end{array}$ & $\begin{array}{c}\text { Rural } \\
\text { Model } 5\end{array}$ & $\begin{array}{c}65 \text { - } 74 \\
\text { Model } 6\end{array}$ & $\begin{array}{c}75 \text { - } 84 \\
\text { Model } 7\end{array}$ & $\begin{array}{c}85+ \\
\text { Model } 8\end{array}$ \\
\hline
\end{tabular}

\section{Kinship network variables}

1) If children lived nearby frequently visited

$\begin{array}{cccccccr}-.23 * & -.43 * & -.11 & -.33^{*} & -.08 & -.62 & .10 & -.37 * \\ -.07 * & -.04 & -.07 & .01 & -.16 * * * & -.01 & -.04 & -.07 \\ .01 & -.01 & .02 & .03 & -.04 & .04 & .02 & .01\end{array}$

3) \# of daughters alive

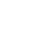

1) Self-rated health

2) $\mathrm{ADL}$

3) Chronical illness

$\begin{array}{cccccccc}.07 & .10 & .06 & .04 & .09 & .10 & -.04 & .12^{*} \\ .78 * * * & .74 * * * & .78 * * * & .71 * * * & 0.87 * * * & .67 & .63 * * & .93 * * * \\ .16 & .07 & .28 * & .15 & .16 & 1.02 * & -.01 & .16\end{array}$

Economic resources variables

1) Household income of last year

2) Education

3) Had pension

4) Homeownership

Other variables

1) Social integration

2) Preferred living with others

Control variables

1) Currently married

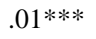

$.01^{* * *}$

$.01^{* * * *}$

$.01^{* * *} \quad .01^{* * *}$

$.01 * * *$

$.01^{* * *}$

$-.03^{* *}-.01 \quad-.01$

$-.01 \quad-.03$

$-.01$

$-.01-.08 * *$

$-.27 * *$

$-.03-.52 * *$

$-.25-.15$

$.11-.43 *-2.3$

$.44 * *$

$.64 * *$

.27

$.32 * * \quad .75 * *$

$.58 * \quad .55^{*} \quad .38^{*}$

2) Ethnicity

3) Sex

4) Urban

$-.21 *$

$.02-.49 * *$

$-.22-.36 *$

$-.77^{* *}-.03-.13$

$1.29 * * *$

$1.39 * * * \quad 1.31 * * *$

$1.20 * * \quad 1.61^{* * *}$

$.90^{* * *} \quad 1.10^{* * *} \quad 1.91^{* * *}$

5) Age

$3.25^{* * *}$

$3.4 * * * \quad 2.94 * * *$

$3.1^{* * *} \quad 3.2^{* * *}$

$3.5^{* * *} \quad 3.1^{* * *} \quad 2.6^{* * *}$

$\begin{array}{llllllll}.79 * * & .15 & 1.31^{* * *} & .75^{* *} & .81^{* *} & .15 & 1.6 * * * & .58^{*}\end{array}$

$-.27 * * *$

$-$

(1)

$-.27 * * *-.35 * *$

$-.54 * * \quad .11 \quad-.33 * *$

$-.05$

$-.13 \quad .01$

$.03 * * *$

$.04 * * * \quad .04 * * *$

$.04 * * * \quad .04 * * *$

$\begin{array}{lll}-.13 & -.01 \quad-.03\end{array}$

Constant

$-4.1 * * *$

$-4.5^{* *}-4.05^{* *}$

$-3.9 * * * \quad-1.9 * * *$

$-1.6 * *$

$-1.5^{* *}-1.3^{* * *}$

$\mathrm{N}$

4753

$2242 \quad 2512$

$2723 \quad 2030$

1038

$1436 \quad 2279$

Pseudo R2

.26

$.30 \quad .23$

$.23 \quad .27$

.40

.29

.19

Source: see s. $*<.1, * *<.05, * * *<.01$.

(CEB) variable does not have significant effect on living arrangements in any models. Since CEB is found to be highly correlated to number of sons and daughters alive, I decided to drop the CEB variable in all models. A greater number of surviving sons and having children visiting the elderly frequently decreases the odds of the elderly to live with family members. The number of surviving daughters and children ever born do not seem to be important factors affecting the elderly's living arrangements. It is a puzzle why having a greater number of surviving sons reduces the likelihood of co-residing. One possible explanation could be that more sons offer more available daily care to the elderly, which diminishes the odds of co-residing.

The coefficients for self-reported health (SRH) and chronical illnesses variables are not significant. Whereas having ADL disabilities increasing the odds of living with others by two times $\left(\mathrm{e}^{(.78)}\right)$, everything else being equal. These results highlight that requiring daily care due to ADL disabilities is a very important factor that 
limits the elderly's living arrangement choices. Among the economic resources variables, having higher household income and ownership of the residence increase the odds of the elderly living with others. In contrast, having higher educational level and pension coverage decreases the odds of the elderly to co-reside with other family members. This is perhaps because that higher education and pension coverage indicate more financial independence, which gives the elderly freedom to choose not to co-reside. The occupational status variable and the main financial support variable are removed from the models because the education and occupational status variables are highly correlated with each other. The same thing happens to the pension coverage and main financial support variables. After running separate analyses and estimations, I decided to use the educational variable and the pension variable since they are better predictors of living arrangements.

The findings also demonstrate that participating in social activities reduces the odds of the elderly living with others by $19 \%\left(\mathrm{e}^{(.78)}\right)$, holding constant the other variables. A strong preference of co-residing also significantly increases the odds of living with others by almost four times $\left(\mathrm{e}^{(1.3)}\right)$. In model 1 , except for the urban residence variable, all the other control variables are significant, meaning that being currently married, female and minority increases the odds of co-residing. The odds of co-residing also increase with age.

Models 2 through 8 show the logistic regression results for subgroups. As we can see, the significant and positive effects of ADL disabilities (except for age group 65 to 74), household income, homeownership (except for females) and preferred living arrangement patterns remain constant across all models. The effect of children's frequent visit variable becomes not significant for females, rural residents or elderly under age 85 . The effect of number of surviving sons only remains significant for rural residents and it turns to be nonsignificant for the rest of the subgroups. Having chronical illnesses prior to the survey year significantly increases the relative odds of living with other family members for females and elderly aged 65 to 74 . Having pension coverage shows significantly negative effect on co-residence among females and the elderly aged 74 to 85 . Social integration does not show significant effect on living arrangements of men, urban residents' or seniors aged 75 or above.

Clearly these results suggest that the Chinese elderly's living arrangement patterns are in part associated with differences in characteristics and kinship, economic, social resources of the groups even after controlling for the groups' demographic features. Further, the ways in which the factors influence the elderly's living arrangements are not the same across the subgroups. The effects seem to be more similar for males and urban residents than for female and rural residents. And the effects of independent variables on living arrangements of the elderly aged 75 to 84 and 85 and over are more similar as compared to the age group 65 to 74 . It suggests that age 75 might be a bench mark for differentiating the elderly when researching on their living arrangements. Even for variables measuring the same concept, some are better predictors than others. Noting that a higher Pseudo R2 value reflects a better fit of the model to the data, the results suggest that using the same variables to predict the elderly's living arrangements, the variable do a relatively better job for the elderly aged 65 to 74 and for the male group as compared to other subgroups. These findings point out the necessity of constructing different models for the elderly subgroups and exploring relatively more important and appropriate determinants in future. Thus, a logical extension of the present work is to explore other important determinants for each subgroup to improve the fit of models to the data.

\section{Conclusions and Discussion}

The study of the elderly's living arrangements has been based on examining the elderly group as a whole. This research intends to study the elderly's living arrangement patterns and especially the determinants by sex, residence and age. In summary, the findings show that about $80 \%$ of the elderly still chose to co-reside with other family members and only $2 \%$ of them lived in institutions. Having children nearby who visited frequently, high education, pension coverage, and a higher level of social integration generally decrease the odds of co-residing. In contrast, having ADL disabilities, higher household income, homeownership and preferring living with others increase the likelihood of co-residing. Currently married individuals, females and minorities are more likely to live with others. Co-residing also increases with age.

Though the above general pattern shows how various factors affect seniors' living arrangements, subgroup variation is also highlighted in this research. Specifically, male and urban residents' living arrangement determinants are more similar, whereas female and rural residents' co-residing determinants are more comparable. Suffering from chronical illnesses instead of ADL disabilities turns to be a more important factor promoting coresiding for females and seniors aged 65 to 74 only. ADL disabilities are found to be a main factor that restricts 
other subgroups to live alone. Age of 75 is found to be a bench mark differentiating living arrangement patterns and determinants for seniors. Pension coverage only significantly decreases the likelihood of co-residence for females and seniors aged 74 to 85 . Social integration diminishes the odds of co-residing for females, rural residents and the elderly aged 65 to 74 . These findings on subgroup variation have not been shown in previous research studying the elderly's living arrangements. The results call future research attention to constructing separate models for the elderly subgroups.

In addition to the new findings, this research also contributes to the field by raising some important concerns. It is predicted that with modernization characterized by the demise of the extended family, increased labor force participation of women and labor mobility, informal care provided by family members will diminish. This transition will place pressure on publicly provided institutionalized care. The data show that about $80 \%$ of the Chinese elderly still chose to live with other family members. Only about $2 \%$ of the elderly lived in institutions. Thus, China has not gone into the stage that a high percentage of seniors live in institutions although there is certainly an urging need for improving public old-age care facilities. I argue that in Chinese society that cherishes filial piety and offers very limited resources of public care services, most of the elderly will still rely on families for long-term care. A follow-up question would be how to improve the quality of home care. With the life expectancy getting longer, more and more seniors are able to live healthily in old age and some of them may only need old-age care in their very late ages. Then home care turns to be multi-formatted. Besides co-residing with family members to receive care, the elderly can receive frequent care from family members who live nearby instead of living with them to seek care. This way of care decreases the likelihood of the elderly being institutionalized and reduces the burden of families to carry long-term old-age care. My research indeed emphasizes that children's frequent visit is one of the keys reducing the likelihood of co-residing. This finding is an important addition to the existing literature that highlights having surviving offspring is the key that determines if the elderly choose to live independently (Guo Zhigang, 2002). In fact, my findings show whether the children provide frequent care is the key. Thirdly, in terms of improving the quality of family care, this research points out that high socioeconomic status increases the odds of the elderly to live with others to receive care. One important finding of this research is that seniors with homeownership tend to live with other members. This is perhaps because in China, owning a home served as a form of wealth attracts offspring to live with the elderly and provide care. This finding reminds policy makers that offering certain kinds of social welfare, including housing benefits to the elderly may be one way to ease the increasing old-age care burden to the society. Since the findings of this research also show that the effect of homeownership on living arrangements does not vary by residence, social policies should not target on urban residents alone. Lastly, my research finds that older seniors, females, minorities, and rural residents are more likely to live with others rather than living in institutions or living alone. This finding suggests that these socioeconomically more disadvantaged individuals that require family care more should perhaps be the focus of future research and main targets of our old-age care policies in the long run.

\section{Funding}

Supported by Program for Young Innovative Research Team in China University of Political Science and Law.

\section{Note}

Data used for this research were provided by the Chinese Longitudinal Healthy Longevity Survey (CLHLS), managed by the Center for Healthy Aging and Family Studies, Peking University. This survey is supported in part by funds from Duke University under an award from the US National Institutes of Aging and by the matching support of Chinese institutions.

\section{References}

Burr, J. A., \& Mutchler, J. E. (1992). The Living Arrangements of Unmarried Elderly Hispanic Females. Demography, 29, 93-112. http://dx.doi.org/10.2307/2061365

Chen Yen-Jong, \& Chen Ching-Yi (2012). Living Arrangement Preferences of Elderly People in Twaiwan as Affected by Family Resources and Social Participation. Journal of Family History, 37, 381-394.

http://dx.doi.org/10.1177/0363199012440948

Costa, D. L. (1997). Displacing the Family: Union Army Pensions and Elderly Living Arrangements. The Journal of Politi- 
cal Economy, 105, 1269-1292. http://dx.doi.org/10.1086/516392

Costa, D. L. (1999). A House of Her Own: Old Age Assistance and the Living Arrangements of Older Nonmarried Women. The Journal of Political Economy, 72, 39-59.

Durkheim, E. (1951). Suicide: A Study in Sociology. Glencoe, IL: The Free Press.

Edmonds, C., Mammen, K., \& Miller, D. L. (2005). Rearranging the Family? Income Support and Elderly Living Arrangements in a Low Income Country. Journal of Human Resources, 40, 186-207.

Engelhardt, G. V., Gruber, J., \& Perry, C. D. (2005). Social Security and Elderly Living Arrangements. Journal of Human Resources, $X L$, 345-372.

Gu, D., Dupre, M. E., \& Liu, G. (2007). Characteristics of the Institutionalized and Community-Residing Oldest-Old in China. Social Science \& Medicine, 64, 871-883. http://dx.doi.org/10.1016/j.socscimed.2006.10.026

Guo Zhigang 郭志刚 (2002). Zhongguo gaoling laoren de juzhu fangshi jiqi yingxiang yinsu 中国高龄老人的居住方式及 其影响因素. Renkou Yanjiu, 26, 37-42.

Kim, I., \& Choe, E. H. (1992). Support Exchange Patterns of the Elderly in the Republic of Korea. Asia-Pacific Population Journal, 7, 89-104.

Li, L. W., Zhang, J., \& Liang, J. (2009). Health among the Oldest-Old in China: Which Living Arrangements Make a Difference? Social Science \& Medicine, 68, 220-227. http://dx.doi.org/10.1016/j.socscimed.2008.10.013

Mutchler, J. E., \& Burr, J. A. (1991). A Longitudinal Analysis of Household and Nonhousehold Living Arrangements. Demography, 28, 375-390. http://dx.doi.org/10.2307/2061463

Shen Ke 沈可 (2010). Yanglao baoxian de puji shifoudaozhi chengzhen duju laoren de zengjia 养老保险的普及是否导致 城镇独居老人的增加? Nanfang Jingji, 6, 17-26.

Soldo, B. J. (1980). America's Elderly in the 1980s. Population Bulletin, 35, 1-48.

Wolf, D. (1984). Kin availability and the Living Arrangements of Older Women. Social Science Research, 13, $72-89$. http://dx.doi.org/10.1016/0049-089X(84)90005-X

Wolf, D., \& Soldo, B. J. (1988). Household Composition Choices of Older Unmarried Women. Demography, 25, 387-404. http://dx.doi.org/10.2307/2061539

Worobey, J., \& Angel, R. J. (1990). Functional Capability and Living Arrangements of Unmarried Elderly Persons. Journal of Gerontology, 45, S95-S101. http://dx.doi.org/10.1093/geronj/45.3.S95

Wu, B., \& Caro, F. G. (2009). Workforce Issues in Residential Care Facilities in Rural China. Journal of Housing for the Elderly, 3, 227-242. http://dx.doi.org/10.1080/02763890903035597

Zeng, Y., Vaupel, J. W., Xiao, Z., Zhang, C., \& Liu, Y. (2002). Sociodemographic and Health Profiles of the Oldest Old in China. Population and Development Review, 28, 251-273. http://dx.doi.org/10.1111/j.1728-4457.2002.00251.x

Zhang Zhen 张震 (2001). Zhongguo gaoling laoren juzhu fangshi de yingxiang yinsu yanjiu 中国高龄老人居住方式的影 响因素研究. Zhongguo Renkou Kexue, S1, 71-77. 
Scientific Research Publishing (SCIRP) is one of the largest Open Access journal publishers. It is currently publishing more than 200 open access, online, peer-reviewed journals covering a wide range of academic disciplines. SCIRP serves the worldwide academic communities and contributes to the progress and application of science with its publication.

Other selected journals from SCIRP are listed as below. Submit your manuscript to us via either submit@scirp.org or Online Submission Portal.
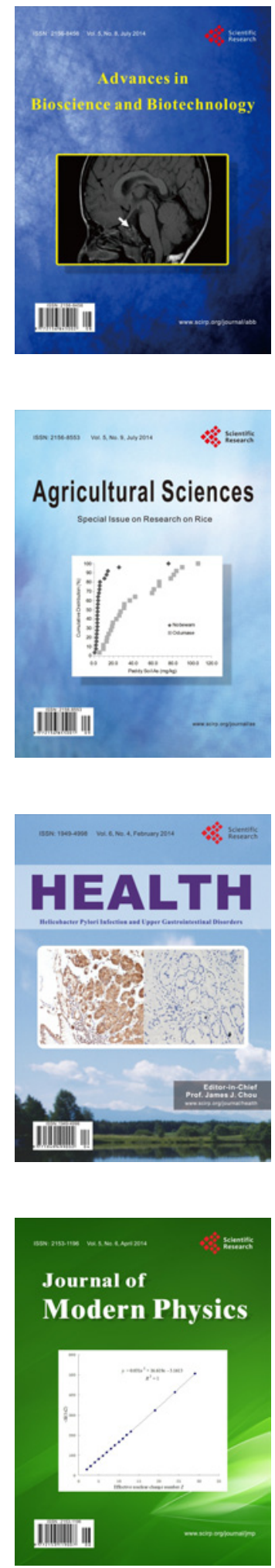
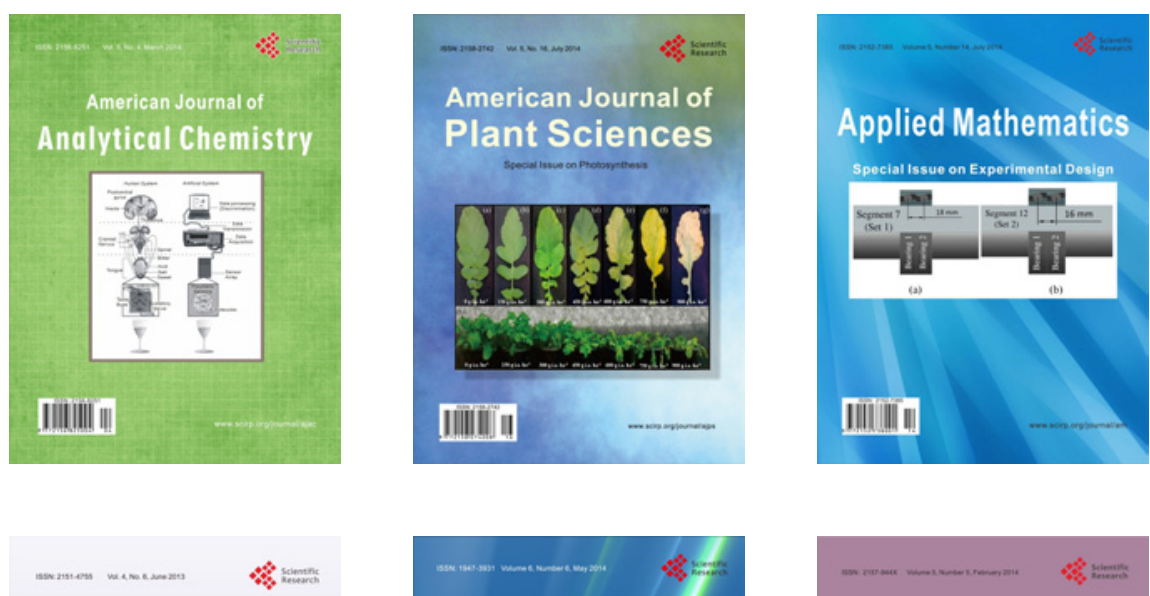

Creative Education
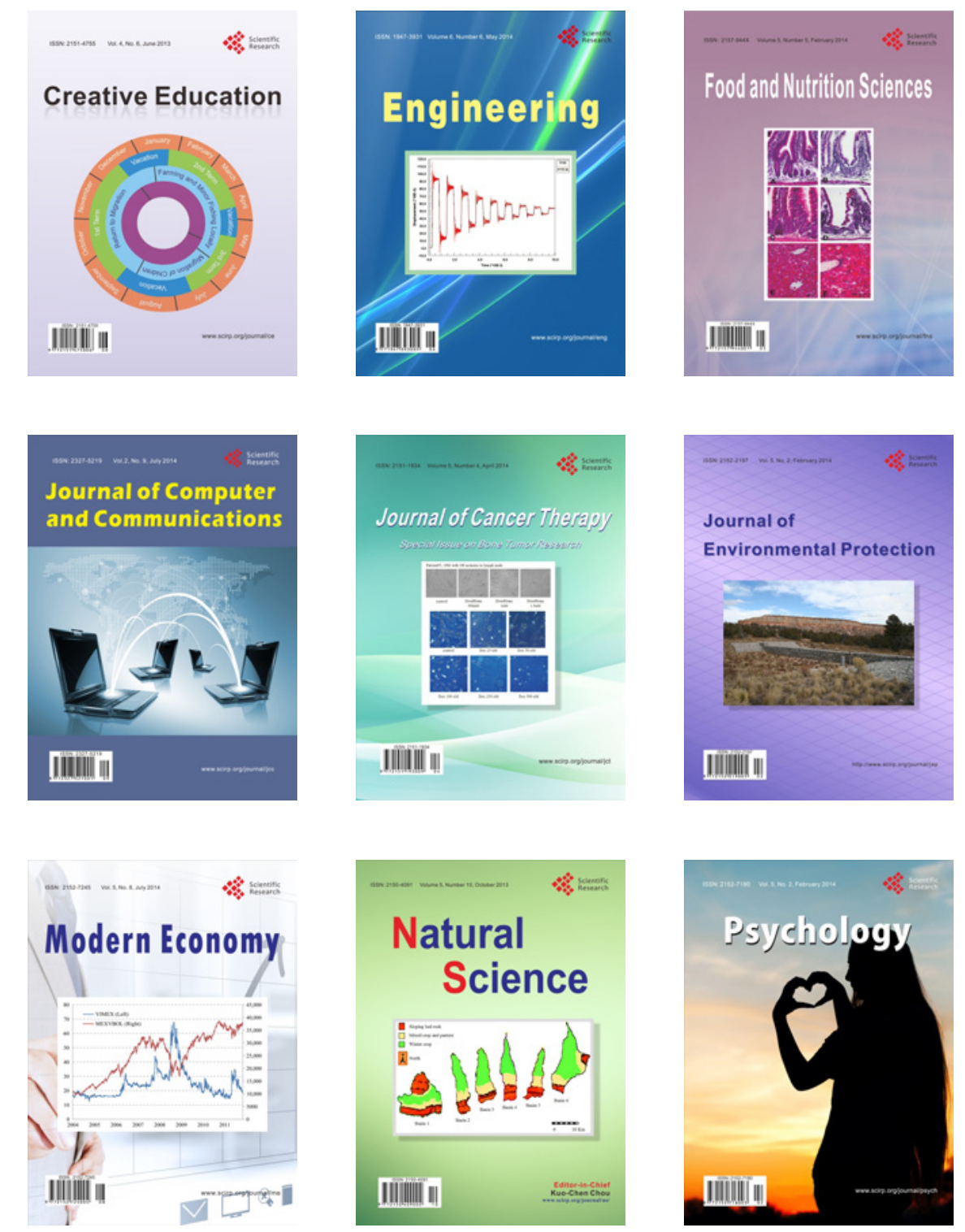